\title{
Involucrando a la familia en la comprensión lectora en los estudiantes del nivel primario
}

\section{Involving the family in reading comprehension in primary level students}

\author{
Juliana Guadalupe Moreno*I \\ *Departamento Académico de Educación, Facultad de Educación, Universidad Nacional del Centro del Perú (UNCP), Huancayo-Perú.
}

\begin{abstract}
Resumen
El presente artículo tiene por objetivo fomentar la comprensión lectora familiar, para lo cual se utilizó el método de la investigación acción educativa que es una construcción de experiencias que se desarrolla a través de la observación mediante la interacción y comunicación de los participantes. Consta de las siguientes etapas: diseño general del proyecto, identificaciones del problema trascendente, análisis del problema, formulaciones del plan de acción, recolección de la información necesaria, categorizaciones de información, estructuraciones de las categorías, ejecuciones de un plan de acción, evaluaciones de la acción ejecutada y propuestas estéticas emergentes. Con la finalidad de descubrir la naturaleza de un problema comunitario o personal, plantear y lograr una solución en un proceso cíclico.
\end{abstract}

Palabras Claves: Investigación acción, lectura en familia, comprensión lectora.

\begin{abstract}
This article aims to promote family reading comprehension, for which it was used the method is a construction of experiences that is developed through observation through interaction and communication of the participants. It consists of the following stages: stage one general project design, stage two identifications of the transcendent problem, stage four formulations of the action plan, stage five. Collection of the necessary information, stage six categorizations of information, stage seven structuring of the categories, stage eight executions of an action plan, stage nine evaluations of the action carried out, stage ten emerging aesthetic proposals. In order to discover the nature of a community or personal problem, pose and achieve a solution in a cyclical process. (Martinez, 2004).
\end{abstract}

Keywords: Action research, family reading, reading comprehenon.

1 Correspondiencia: Juliana Guadalupe Moreno, juli23161229@gmail.com 


\section{Envolver a familia na compreensão de leitura em estudantes de nível primário}

\section{Resumo}

Este artigo tem como objetivo promover a compreensão da leitura familiar, para a qual foi utilizado o método da pesquisa-ação educativa, é uma construção de experiências que se desenvolve por meio da observação por meio da interação e comunicação dos participantes. Consiste nas seguintes etapas: estágio um desenho geral do projeto, estágio dois identificações do problema transcendente, estágio três Análise do problema, estágio quatro formulações do plano de ação, estágio cinco. Coleta das informações necessárias, estágio seis categorizações de informações, estágio sete estruturação das categorias, estágio oito execuções de um plano de ação, estágio nove avaliações da ação realizada, estágio dez propostas estéticas emergentes. Para descobrir a natureza de um problema comunitário ou pessoal, propor e alcançar uma solução em um processo cíclico.

Palavras clave: Pesquisa-ação, leitura em família, compreensão de leitura.

\section{Ayllu uñuna lectura atinapaq llapallan yachaqkunata nivel primariota}

\section{Uchuycha}

Kayarticulunchuran chay método de la investigación acciónyachay kan ayllupuqpusaywachakuy chay yachaykunaqawarisqa rimanaqusqapillapallanuñuchasqakunapi. Kaypin kan huk diseño general ruwaykama, iskas etapa riqsispasasaykunata, iskay, tawa etapa ruwaspa plan de acción nisqan, pichqa etapa. Pallaspawillayta, suqta etapa willaytacaterogorizacionispa, qanchis etapa estructuraspacategoriaskunata, pusaq etapallamkana planaccionta, isqun etapaevaluaspa acción ruwasqata, chunkaetapa propuestas sumag emergente. Tukuyta tarispaallpakausaytahuk problema saspiichasapallan, tarispa kaspaspa chay proceso ciclikupi.

\section{Hatun apup simi:}




\section{Introducción}

Lectura en familia es una actividad muy placentera que ayuda a juntar lazos entre padres e hijos favoreciendo a todos. Consiste en diseñar un proyecto de lectura familiar, aplicar el plan de acción, recolectar información literal, inferencial y crítica, categorizar y ejecutar lo aprendido en la lectura de textos. Para que los niños descubren el mundo mediante imágenes y distintos textos los padres aprendemos nuevas formas de relacionarnos con nuestros niños (Dulcic, 2009).

Ya que dentro de ella los adultos educan, transmiten valores y formas de vida a los niños y niñas que la conforman. Cómo padres, se quiere lo mejor para los hijos, y la lectura en familia es el punto de partida que día a día ayudará a mejorar la comprensión lectora de sus hijos. Esta aproximación al universo formativo que los padres realizaron en cuanto a la capacidad lectora.

Podemos transformar en recursos valiosos que estimulan el proceso de habilidades que favorecen la forma para comprender diversos textos. Por lo que en este artículo se pretende demostrar que la lectura familiar mejora la construcción de nuevos conocimientos que nos permiten favorecer el desarrollo de los niveles de comprensión lectora en los niños y niñas.

Es por ello, se debe de involucrar a los integrantes de la familia en el desarrollo de la práctica lectora, muchas veces se considera que las enseñanzas de la lectura deben de realizarlo dentro de un aula de clases de una escuela, pero no debe ser así porque las familias se constituyen en ámbitos favoritos para iniciar una mediación en cuanto a la lectura, los padres deben influenciar directamente convirtiéndose en modelos y guías de sus hijos.

No solo es positiva para la creatividad y la imaginación, sino también es una herramienta fundamental para el diálogo entre padres e hijos, y así intercambiar sentimientos y emociones, que a veces cuesta tanto expresar. El fomento de la lectura en familia se debe desarrollar en espacios, y ambientes cómodos y confortables; su desarrollo no está inscrito en un currículo.

De esta manera se puede mejorar la práctica de la lectura en entornos familiares, y lograr potenciar como lectores a los estudiantes de los distintos contextos socioculturales, es muy importante el desarrollo de estímulos del ambiente que los rodea y las relaciones que se tiene como padre con nuestros hijos sirviendo como modelos, de esta manera ellos también se motivan en las actividades que realizan, observando a sus padres como lectores activos.

El proyecto de investigación acción se diseñó siguiendo los siguientes pasos: se les explicó las bondades de una lectura familiar, se realizó compromisos con el familiar, tiempos de lectura, lugar de lectura, lecturas o textos, música, los procesos ANTES de la lectura, DURANTE la lectura y DESPUÉS de la lectura las familias deben identificar la idea principal y subrayar con lápiz de colores las personajes y hechos importantes de la lectura.

El problema detectado es que las familias no practican la lectura familiar por lo tanto no comprenden lo que leen, por lo que se formula la siguiente pregunta ¿Cómo perciben los estudiantes la comprensión lectora familiar en la lectura de diversos textos?

Del cuestionario realizado a la familia Llacza sobre Lectura Familiar se puede rescatar lo siguiente: que sus ratos libres son aprovechados para conversar sobre temas ya leídos en textos, revistas, diarios, etc.; las lecturas realizadas en familia concluyen en comentarios, críticas y análisis de lo leído enriqueciendo al conocimiento familiar y ayudando a la unidad familiar; la familia Llacza cuenta con un espacio propio y agradable para la lectura.

Así mismo cabe resaltar que los malos hábitos identificados son: no tienen la costumbre de ir a la librería a comprar libros nuevos; no leen antes de dormir; no tienen la costumbre de escoger libros que leerán en familia; no leen en sus ratos libres en familia debido a que no tienen práctica lectiva y desconocen los beneficio, por ello trae como consecuencia poca comprensión cuando leen un texto. 
Tabla 1. Plan de acción desarrollada en la familia de Elvis Llacza

\begin{tabular}{|c|c|c|c|c|c|c|}
\hline Objetivos & Acciones & Tiempo & Estrategia & Canales & Responsabilidades & Indicador \\
\hline \multirow{3}{*}{$\begin{array}{l}\text { Identificar como } \\
\text { perciben las familias } \\
\text { la comprensión } \\
\text { lectora para la mejora } \\
\text { de sus prácticas de } \\
\text { lecturas familiares. }\end{array}$} & $\begin{array}{l}\text { Organizar el equipo } \\
\text { de trabajo familiar. } \\
\text { Animación a la } \\
\text { lectura familiar. }\end{array}$ & $60 \mathrm{~min}$ & $\begin{array}{l}\text { Mencionan sus actividades favoritas. } \\
\text { Presenta títulos de posibles textos a } \\
\text { leer. } \\
\text { Escoger un horario de lectura. }\end{array}$ & $\begin{array}{l}\text { WhatsApp. } \\
\text { Zoom. }\end{array}$ & $\begin{array}{l}\text { El investigador. } \\
\text { El estudiante } \\
\text { Padres de familia }\end{array}$ & \begin{tabular}{|l|} 
Establecer el \\
tiempo de lectura \\
familiar.
\end{tabular} \\
\hline & $\begin{array}{l}\text { Realizar } \\
\text { compromisos para } \\
\text { implementar una } \\
\text { biblioteca en la casa. }\end{array}$ & $30 \mathrm{~min}$ & $\begin{array}{l}\text { Enviar lecturas virtuales diarias. } \\
\text { Elijamos una lectura de su interés. } \\
\text { Biblioteca en casa. }\end{array}$ & & & $\begin{array}{l}\text { Aprendiendo } \\
\text { juntos. }\end{array}$ \\
\hline & $\begin{array}{l}\text { Se le brindará } \\
\text { conocimientos sobre } \\
\text { los procesos de } \\
\text { lectura. } \\
\text { Las lecturas diarias. }\end{array}$ & $30 \mathrm{~min}$ & $\begin{array}{l}\text { Leer en voz alta. } \\
\text { Antes } \\
\text { Durante } \\
\text { Después. } \\
\text { Deben participar todos los miembros } \\
\text { de la familia. }\end{array}$ & $\mid \begin{array}{l}\text { Zoom } \\
\text { Google drive. }\end{array}$ & & $\begin{array}{l}\text { Piensa y expresan } \\
\text { sus ideas. }\end{array}$ \\
\hline
\end{tabular}

\section{Comprensión lectora de la familia Llacza}

Para la familia de Elvis Llacza la lectura tiene la virtud de convertirse en una experiencia de encuentro en el hogar, debemos actuar como mediadores efectivos de la lectura en aquellas familias donde aún no se practican la lectura familiar (Pekeleke, 2015). "Leer en familia es una actividad muy divertida que ayuda a estrechar lazos entre padres e hijos y nos enriquece a todos."

\section{Comprensión lectora de la familia de Elvis Llacza}

Es la capacidad para entender lo que se lee y el proceso de interrelación entre la familia de Elvis Llacza. Identificando en los textos los niveles de comprensión lectora nivel literal, inferencial y crítico, leyendo, releyendo, subrayando los personajes, escenario, lugar donde ocurren los hechos, ideas principales del texto; para encontrar el significado de las palabras y el mensaje.

Según el Ministerio de Educación la comprensión lectora es “una interacción dinámica entre el lector, el texto y los contextos socioculturales que enmarcan la lectura" (MED, 2017, pág. 159).

Estrategias que practican la familia de Elvis Llacza después de la aplicación del plan de acción de la lectura familiar son los siguientes. Ellos leen en voz alta durante la práctica de la lectura familiar, dedican 20 minutos diarios a la lectura, leen en las noches porque es el momento donde todos pueden estar, tienen un lugar cómodo, confortable y sin distracciones para leer, generalmente leen periódicos y libros de cuentos, practican la alternancia.

Del cuestionario realizado a la familia Llacza sobre la fábula "El león y el ratón." se puede rescatar lo siguiente: después de haber leído la lectura y respondido el cuestionario se puede afirmar en cuanto al nivel literal, respondieron correctamente y la pregunta realizada fue la siguiente ¿Cómo pilló el león al ratón? respondieron desprevenido, ¿De qué cayó preso el león? respondieron de una trampa ¿Cómo encontró el ratón al león cuando llegó? respondieron exhausto de tanto gritar, ¿Cómo encontró el ratón al león cuando llegó?, en el nivel inferencial a la pregunta ¿Qué aprendimos de estas acciones del ratón y el león? respondieron que nunca debemos despreciar ni menospreciar a los demás ni ser prepotentes, porque la vida da muchas vueltas. 
¿En qué momento el ratoncito demostró lealtad a sus palabras? respondieron cuando el ratón rescata al león como agradecimiento. En cuanto al nivel crítico se planteó las siguientes preguntas ¿Debemos valorar a las personas por su apariencia? la familia dice No, porque todas las personas somos iguales. ¿Cómo se sentiría el león, si el ratón no cumple su promesa? se sentiría triste y decepcionado. Entonces se pude afirmar que la familia de Elvis Llacza comprende textos que leen en familia.

Los niveles de comprensión lectora para la familia de Elvis Llacza en cuanto al nivel literal es la capacidad que tienen para evocar sucesos o hechos tal como aparecen expresados en la lectura. En el Nivel Inferencial son capaces de deducir o inferir ideas o informaciones que no han sido señaladas o expresadas de manera explícita en el texto.

En el nivel crítico lograron interpretar y obtener una mejor comprensión que les permite expresar sus opiniones y emitir juicios en relación al texto, pueden reflexionar sobre el contenido del mismo a fin de emitir un juicio crítico valorativo o una opinión sobre lo leído.

Se realizó la animación a la lectura familiar durante 30 minutos, se explicó las bondades de una lectura familiar y la repercusión en el futuro. Por lo cual se realizó compromisos para implementar una biblioteca en la casa y un horario de lectura familiar, el tiempo establecido para la lectura con la familia de Elvis Llacza, fue que durante todo el día leerán 30 minutos.

También se brindó una charla sobre los procesos de lectura. Antes de la lectura siempre se deben realizar la motivación, objetivos, revisión y actualización del conocimiento previo, establecer predicciones, generar preguntas y repreguntas. Durante la lectura deben compartir padres e hijos, lectura en voz alta y silenciosa, la ruleta de colores para subrayar las ideas principales, personajes y lugar. Después de la lectura las familias deben mencionar la idea principal, el resumen, formular y responder preguntas y repreguntas.

El instrumento utilizado fue el cuestionario que es un conjunto de preguntas que fueron elaboradas para generar los datos necesarios y lograr los objetivos propuestos. También nos permiten generalizar los procesos de recopilación de datos. Si el instrumento es inadecuado, llevaría recoger información incompleta, datos no precisos. Este cuestionario fue aplicado a la familia de Elvis Llacza para recabar información.

Luego de la aplicación de la estrategia puedo decir que la estrategia lectura en familia logra mejorar la comprensión lectora en los estudiantes y los hábitos de lectura. También permite abrir espacios para compartir el gusto por la lectura, esta estrategia está dirigido a todos los padres de familia para conversar y construir sentidos colectivos a partir del texto leído con las lecturas seleccionadas por las familias; sin embargo, para que el fomento de la lectura sea exitoso debemos lograr el placer por la lectura desde temprana edad.

\section{Conclusiones}

Con la aplicación de la investigación acción educativa se logró mejorar la práctica de la lectura familiar mediante la ejecución activa de los siguientes pasos: implementar, temporizar, contextualizar, objetivos, y la evaluación para apreciar el logro programado.

Para concluir les recomiendo que como padres de familia debemos realizar la tan preciada actividad de leer junto a sus hijos. De esta manera podemos incentivar a que lean y a la vez leerles, es una actividad muy interesante para estimular a los hijos la creatividad. 


\section{Referencias Bibliográficas}

Cerrón, W. (2019). La investigación cualitativa en educación. Horizonte de la Ciencia, 159- 167.

Dulcic. (2009). Leemos Juntos. MINEDUC.

Educación., M. d. (2017). Programa curricular del nivel primario. Lima: Ministerio de Educación.

Hernández-Sampieri, R. \&. (Ciudad de México: Mc Graw Hill Education). Metodología de la Investigación. Las rutas cuantitativa, cualitativa y mixta, 2019.

Martínez. (2004). Ciencia y arte en la metodología cualitativa. México: Reg.

MED. (2017). Programa curricular del nivel primaria. Lima: Ministerio de Educación.

Pekeleke. (2015). La importancia de la lectura en familia. Chile. Obtenido de https://pekeleke.es/blog/laimportancia-de-la-lectura-enfamilia/\#: :text=Leer\%20en\%20familia\%20es\%20una,de\%20relacionarnos\%20 con\%20nuestros

Sole. (1992). Estrategias de lectura. Editorial GRAÓ.

Sole. (2009). Estrategias de la Lectura. Madrid. 